\title{
The impact of legalization of access to recreational Cannabis on Canadian medical users with Cancer
}

\author{
Philippa Hawley ${ }^{1,2^{*}}$, Monica Gobbo ${ }^{1}$ and Narsis Afghari ${ }^{1}$
}

\begin{abstract}
Background: Canada legalized cannabis use for medical purposes in 1999. Legalization of cannabis for recreational purposes in October 2018 offered the opportunity to assess the impact of recreational legalization on cancer patients' patterns of use to identify learning points that could be helpful to other countries considering similar legislation.
\end{abstract}

Method: Two identical anonymous cross-sectional surveys were administered to cancer patients in British Columbia 2 months before and 3 months following legalization, with the same eligibility criteria.

The prevalence of medical cannabis use, the distribution of symptoms leading to use, the most common types of cannabis products and sources, reasons for stopping using cannabis, and barriers to access were assessed.

Results: The overall response rate was 27\%. Both cohorts were similar regarding age (median =66 yrs), gender (53\% female), and education (approximately $85 \%$ of participants had an education level of high school graduation and higher). Respondents had multiple motives for taking cannabis, including to manage multiple symptoms, to treat cancer, and for recreational reasons. The majority of patients in both surveys did not use the legal medical access system.

Comparison of the two cohorts showed that after legalization the prevalence of current cannabis use increased by $26 \%$ (23.1\% to $29.1 \%, p$-value 0.01 ), including an increased disclosure of recreational motive for use, from 32 to $40 \%$. However, in the post-legalization cohort more Current Users reported problems getting cannabis (18\%) than the pre-legalization cohort (8\%), ( $p$-value $<0.01)$. The most common barrier cited was lack of available preferred products, including edibles, as these were only available from illegal dispensaries.

Conclusions: Results showed that legalization of cannabis for recreational purposes may have an impact on those who use medical cannabis. Impacts include an increase in prevalence of use; problems accessing preferred products legally; higher cost, and difficulties using a legal access system. The desired goal of regulation in reducing harms from use of illegal cannabis products are unlikely to be achieved if the legal process is less attractive to patients than use of illegal sources.

Keywords: Cannabis, Cancer, Survey, Symptom management

\footnotetext{
* Correspondence: phawley@bccancer.bc.ca

${ }^{1}$ Pain and Symptom Management/Palliative Care, British Columbia Cancer,

600 W 10th Ave, Vancouver, BC V5Z 4E6, Canada

${ }^{2}$ Department of Medicine, University of British Columbia, Vancouver, BC,

Canada
}

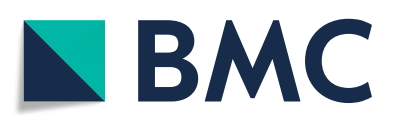

(c) The Author(s). 2020 Open Access This article is licensed under a Creative Commons Attribution 4.0 International License, which permits use, sharing, adaptation, distribution and reproduction in any medium or format, as long as you give appropriate credit to the original author(s) and the source, provide a link to the Creative Commons licence, and indicate if changes were made. The images or other third party material in this article are included in the article's Creative Commons licence, unless indicated otherwise in a credit line to the material. If material is not included in the article's Creative Commons licence and your intended use is not permitted by statutory regulation or exceeds the permitted use, you will need to obtain permission directly from the copyright holder. To view a copy of this licence, visit http://creativecommons.org/licenses/by/4.0/ The Creative Commons Public Domain Dedication waiver (http://creativecommons.org/publicdomain/zero/1.0/) applies to the data made available in this article, unless otherwise stated in a credit line to the data. 


\section{Background}

Despite encouraging pre-clinical studies, there is little to no human clinical trial evidence of potential for prolongation of survival in cancers other than some small preliminary studies in glioblastoma [1]. Cannabinoids of a variety of types have however been shown to alleviate several symptoms common among cancer patients [2]. Cancer patients report using cannabis extracts and synthetic cannabinoids to manage their cancer-related symptoms, including pain, sleep disturbance, anxiety, nausea, and anorexia [3-7]. Also, other symptom management drug consumption has been found to be reduced among cancer patients using cannabis products [4]. There is, however little research on the benefits and harms of using cannabis-based products for medical purposes [5].

There are currently two cannabis-based pharmaceutical products available by prescription in Canada to people living with cancer, multiple sclerosis or acquired immunodeficiency syndrome (AIDS), for management of pain, muscle spasm, and anorexia respectively. Nabiximols/Sativex ${ }^{\circ}$ ) is prohibitively expensive, and the synthetic tetrahydrocannabinol (THC) analogue nabilone/ Cesamet $^{\circ}$ lacks any of the non-THC components present in naturally occurring cannabis-based products, particularly cannabidiol (CBD), which has been shown to reduce side-effects of THC, and to have independent effects [6-9].

Canada legalized the use of plant-derived cannabis for medical purposes in 1999 allowing medical cannabis producers to become licensed to sell dried plant product and (later) oil extracts to patients online, with stringent quality standards, including clear labelling of THC and CBD content, and documentation of absence of molds or pesticide residues. The legal products were generally more expensive than via the illegal route and the process of accessing them was quite onerous [10]. Edibles (oral capsules, tablets, or cannabis-containing food products) were not permitted. Though there have been different iterations of the process over the years, patients have always had to obtain a "medical authorization" document from their physician and then register with an online supplier, making a mail-order purchase with a credit card [10]. An alternative access route has always existed via illegal but unprosecuted storefront dispensaries and unlicensed growers. In 2000 the Supreme Court of Canada deemed access to cannabis for medical purposes a human right, which made prohibition of these unregulated suppliers virtually impossible. Failure to enforce laws prohibiting sale of cannabis products by unlicensed providers led to a lucrative and unregulated cannabis supply industry, with no medical oversight, no standards, highly variable quality of product, and inconsistent or inappropriate guidance for medical users.
In response to this legal quagmire, the Canadian government announced in early 2018 that as of October 17, 2018, Canada would be the second country in the world (after Uruguay), to set up a separate legal cannabis access system for recreational use [11-13], which from here on will be referred to simply as 'legalization'. After the Cannabis Act came into force, sale, possession, production, and distribution of cannabis in Canada have been legal. Recreational dispensaries (storefront and online) were allowed to apply for permission from Health Canada to sell a variety of cannabis-based products to any purchaser 18 years of age or older, but were not permitted to provide medical information to purchasers. The products had to be derived from a Health Canadaapproved source, and only dried plant product or oils were to be permitted. Neither medical authorization nor Health Canada registration were required for purchase from recreational dispensaries. To protect public safety, a strict legal framework was implemented to control production, and non-oil extracts and topicals remained illegal until one year after legalization [14-16].

Under the new legislation, only licensed dispensaries were allowed to sell legal recreational cannabis products, and many unlicensed dispensaries were forced to close while their license applications were being processed $[15,17]$. At the time of this study, 3 months after legalization, there was only one licensed dispensary open in British Columbia (BC) [18]. Widespread publicity of the planned date of legalization created a unique opportunity to observe the use of cannabis in the medical setting both before and after recreational legalization.

Part I of this study was a survey which was developed and administered roughly 2 months prior to legalization to British Columbia Cancer (BCC) Centre attendees [19]. Results from this survey demonstrated a high usage of cannabis in a variety of forms by cancer patients in BC. Just over half $(52 \%)$ had used cannabis at some point in their lifetime, and most past users reported their prior goal of use to be recreational. Half of those who had ever used cannabis reported currently taking cannabis, i.e. one in four responding cancer patients reported currently taking cannabis or cannabis-based products. The most common reasons for use were for symptoms: pain $(62 \%)$, insomnia (41\%), nausea (39\%), and anxiety (36\%); but many (52\%) reported also ticked the survey option of taking it for 'cancer treatment'.

Though 32\% of Current Users disclosed some recreational reason for use as well as medical, only 6 of the 190 Current Users (3.2\%) stated their use was purely recreational. Current Users tended to primarily use cannabis oil extracts to alleviate multiple symptoms simultaneously, suggesting potential for cannabinoids to substitute for other drugs such as analgesics, antiemetics, hypnotics, and anxiolytics [10]. These results 
were consistent with those of similar studies in Canada which reported on cannabis use in the medical setting prior to legalization $[20,21]$.

The survey was repeated in another cohort of BCC patients randomly selected in exactly the same way, 3 months after legalization, to see if legalization had impacted the prevalence or patterns of use. This report describes the results from the second survey and compares them with the first.

\section{Methods}

The survey and its administration were exactly the same as for the first survey described in detail previously [10]. In brief, the survey was designed to capture cannabis use prevalence and patterns and mailed to all patients who were scheduled for an appointment at any of the six BCC Centres on an arbitrarily chosen study day. As noted in our first report, BCC is a provincial organization and sees $94 \%$ of the total number of cancer patients seen for specialist oncology services each year in BC (Fiscal 2017/2018). The surveyed cohort can therefore be considered representative of the cancer patient population in the province, which includes urban, rural, and remote populations. The one-page survey had been reviewed previously for ease of readability by a group of patient volunteers prior to administration (see Fig. 1). The study was approved by the University of British Columbia Research Ethics Board (H18-01638). Eligibility for a cash prize was offered as an incentive for participation, and lottery entries were separated from the surveys immediately upon opening. All surveys were reviewed anonymously. Returned surveys were collected for 1 month following the study day and entered into the REDCap data capturing system [22, 23]. The first and second surveys were differentiated by paper colour to avoid confusion between the two cohorts.

Respondents were asked to state their age; gender; ethnicity; level of education; primary cancer diagnosis (if any); understanding of treatment stage; current and past cannabis use; form(s) used; source of product(s); rea$\operatorname{son}(\mathrm{s})$ for use; whether they had had any difficulties accessing cannabis; and (if a past user) their reasons for stopping. All information was provided anonymously. The only chart-derived data was the appointment booked on the arbitrarily selected index day (Wednesday January 9th, 2019).

Survey respondents were assigned into user groups (Never, Prior, and Current Users) and within groups into pre- and post-legalization cohorts. Comparisons between groups were made using the chi-square test of independence and two sample $t$-tests.

\section{Results}

The response rate of $27.0 \%$ (852 out of 3167 surveys mailed) was almost exactly the same as for the prelegalization survey mail out; 27.4\% (Fig. 2). Current taking of cannabis was reported by $29.1 \%$ of participants $(n=248)$ (Table 1$)$. Respondent demographics were very similar between the two survey cohorts. In the second (post-legalization) cohort Never, Prior, and Current Users were all very similar in regard to gender, primary cancer diagnosis, treatment stage, and education.

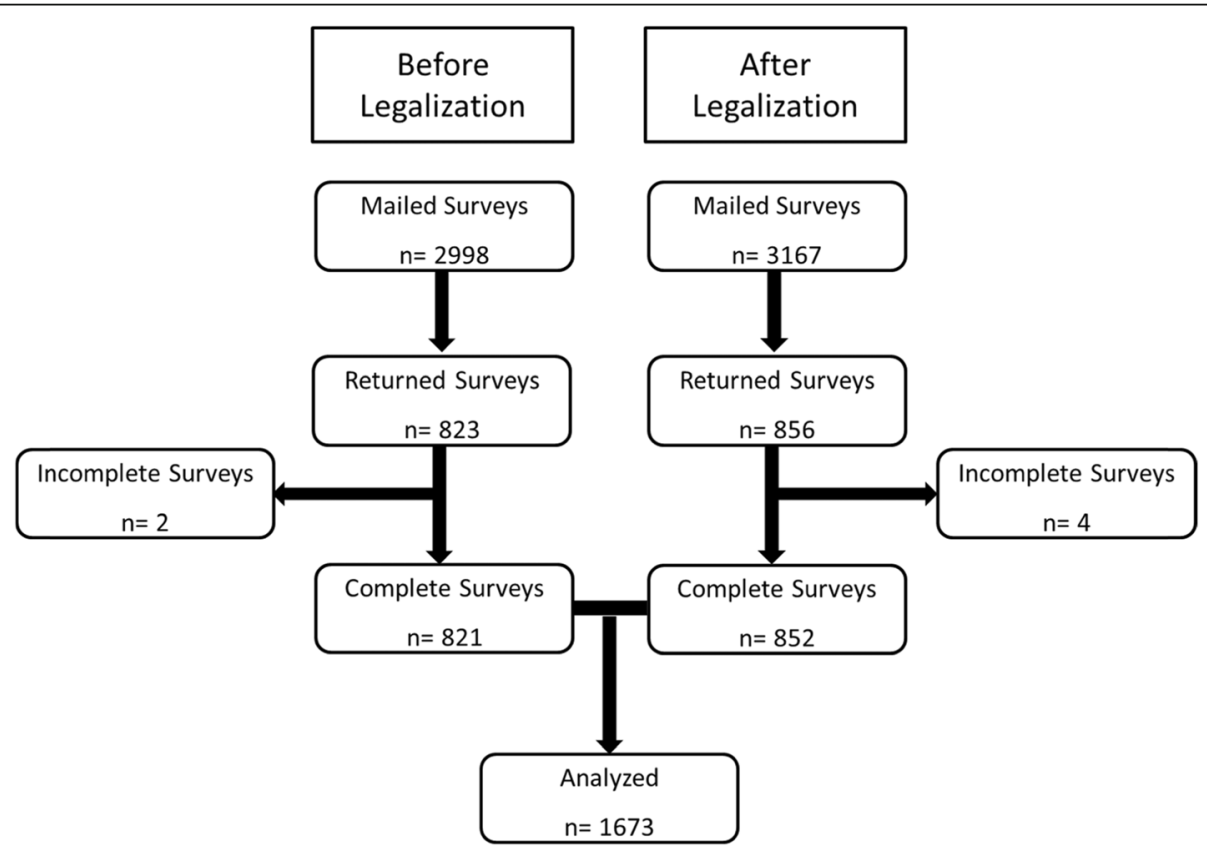

Fig. 1 Consort Diagram 


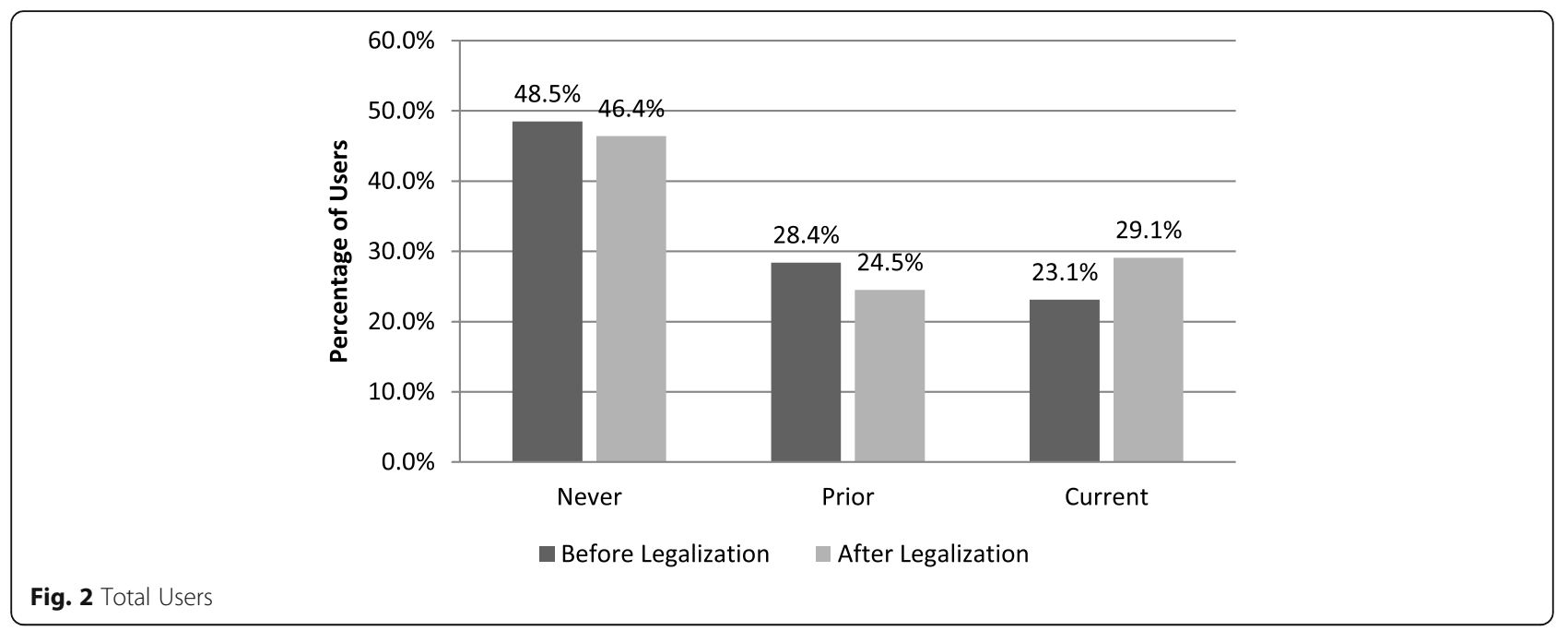

Approximately $85 \%$ of participants had an education level of high school graduation and higher. The majority of participants were Caucasians (81\%) and Asians (7\%). Fifty five percent of Caucasians and 31\% of Asians in this study were prior or current cannabis users (Table 2). Current and Prior Users had a lower median age compared to Never Users $(62,64$, and 70 yrs., respectively; $p$-value $<0.01$ ).

Current Users took cannabis for multiple reasons (Table 3). The most common target symptoms were pain (58\%), insomnia (42\%), anxiety (36\%), and nausea (33\%). Recreational use was disclosed by $40 \%$ of current users and, nearly half (47\%) also used it with a goal of treating their cancer. Prior Users stated their use was most often recreational (58\%), with the next most frequent reason being pain (27\%).

One of the most important findings of this survey was that the majority of current users did not use the legal online system set up for patients to access medical cannabis, despite using it for medical $(n=149)$ rather than recreational use $(n=49)$. Only $27 \%(n=66)$ of Current Users had a medical authorization. This was further broken down to be $30 \%$ of current users who reported using cannabis only for medical purposes and $21 \%$ of current users who reported using cannabis at least partly for recreational purposes.

Table 1 Cannabis use before and after recreational legalization in Canada

\begin{tabular}{lllllll}
\hline & Before & & & After & $\boldsymbol{p}$ \\
& $\boldsymbol{n = 8 2 1}$ & \% & & $\boldsymbol{n}=\mathbf{8 5 2}$ & \% & \\
\hline Users (\%) & a & & & & & \\
Never & 398 & 48.5 & & 395 & 46.4 & 0.01 \\
Prior & 233 & 28.4 & & 209 & 24.5 & \\
Current & 190 & 23.1 & & 248 & 29.1 & \\
\hline
\end{tabular}

${ }^{a} p$ values were calculated using the chi-square test of independence
Current Users obtained their cannabis from a friend (54\%) and from illegal dispensaries (53\%) almost equally. Current Users reported using multiple forms of cannabis products, but used oils the most (70\%) followed by smoking (64\%), eating (48\%), vaporizing (33\%) and topically (29\%) (Fig. 3). Current users were asked if they had problem getting access to cannabis products. Qualitative data were collected through open-ended questions. Forty-four out of 248 Current Users (17.7\%) reported that they had problems getting cannabis, and 41 provided qualitative comments. Three main themes were identified. Sixteen respondents reported specific products were not available, 15 reported having access issues access with dispensaries, and 5 disclosed problems in getting medical authorization. Participants' representative quotes are summarized in Table 4.

For patients reporting prior but not current use, the prior use was often many years previously and had been primarily recreational in intent (58\%). Respondents had stopped because of losing interest; safety concerns; or not having used it since their youth (no specific reason stated). Some had tried it for management of cancer-related symptoms, particularly pain (27\%) and had discontinued it, most often due to lack of effectiveness, but some stopped because of side effects (Table 5).

\section{Impact of legalization}

There was an increase in respondent disclosure of Current Use of cannabis from $23.1 \%$ in the prelegalization cohort to $29.1 \%$ in the post-legalization cohort ( $p$-value $<0.01)$. No significant differences were found among the demographics of groups when comparing pre- and post- legalization. Before legalization, 32\% of Current Users disclosed some recreational motivation for use. After legalization this increased to 40\%, 
Table 2 Demographic comparisons of respondents who are Never, Prior, and Current Users of cannabis before and after legalization of recreational cannabis in Canada

\begin{tabular}{|c|c|c|c|c|c|c|c|c|c|}
\hline & \multicolumn{3}{|c|}{ Never Users } & \multicolumn{3}{|c|}{ Prior Users } & \multicolumn{3}{|c|}{ Current Users } \\
\hline & $\begin{array}{l}\text { Before } \\
n=398\end{array}$ & $\begin{array}{l}\text { After } \\
n=395\end{array}$ & $p$ & $\begin{array}{l}\text { Before } \\
n=233\end{array}$ & $\begin{array}{l}\text { After } \\
n=209\end{array}$ & $p$ & $\begin{array}{l}\text { Before } \\
n=190\end{array}$ & $\begin{array}{l}\text { After } \\
n=248\end{array}$ & $p$ \\
\hline \multicolumn{10}{|l|}{ Age $^{a}$} \\
\hline Median & 70 & 70 & 0.91 & 63 & 64 & 0.03 & 61 & 62 & 0.54 \\
\hline IQR & $61-76$ & $62-77$ & & $54-69$ & $56-71$ & & $52-70$ & $55-69$ & \\
\hline Not Reported & 3 & 3 & & 1 & 2 & & 1 & 1 & \\
\hline \multicolumn{10}{|l|}{ Gender } \\
\hline Female & 213 & 217 & 0.69 & 127 & 115 & 0.86 & 94 & 123 & 0.99 \\
\hline Male & 182 & 175 & & 105 & 92 & & 95 & 124 & \\
\hline Other & 0 & 0 & & 0 & 1 & & 0 & 0 & \\
\hline Not Reported & 3 & 3 & & 1 & 1 & & 1 & 1 & \\
\hline \multicolumn{10}{|l|}{ Race } \\
\hline Caucasian & 284 & 314 & 0.25 & 187 & 181 & 0.22 & 155 & 197 & 0.90 \\
\hline Asian & 49 & 42 & & 10 & 8 & & 7 & 11 & \\
\hline Aboriginal & 6 & 1 & & 4 & 1 & & 8 & 8 & \\
\hline East Indian & 8 & 9 & & 0 & 3 & & 2 & 2 & \\
\hline African American & 1 & 0 & & 0 & 1 & & 2 & 1 & \\
\hline Latin American & 2 & 1 & & 0 & 1 & & 0 & 0 & \\
\hline Other & 25 & 12 & & 20 & 3 & & 11 & 16 & \\
\hline Not Reported & 23 & 16 & & 12 & 11 & & 5 & 13 & \\
\hline \multicolumn{10}{|l|}{ Primary Cancer } \\
\hline Breast & 93 & 102 & 0.23 & 58 & 59 & 0.72 & 31 & 46 & 0.87 \\
\hline Prostate & 59 & 65 & & 27 & 32 & & 26 & 23 & \\
\hline Gastrointestinal & 56 & 42 & & 27 & 23 & & 26 & 44 & \\
\hline Blood/Lymph System & 52 & 46 & & 25 & 23 & & 23 & 29 & \\
\hline Lung & 41 & 32 & & 21 & 14 & & 24 & 24 & \\
\hline Head/Neck & 18 & 20 & & 25 & 17 & & 14 & 19 & \\
\hline Gynecologic & 28 & 19 & & 14 & 9 & & 12 & 13 & \\
\hline Skin & 15 & 11 & & 14 & 7 & & 11 & 14 & \\
\hline Brain & 9 & 9 & & 9 & 6 & & 7 & 7 & \\
\hline Genitourinary & 7 & 13 & & 5 & 4 & & 4 & 7 & \\
\hline Sarcoma & 3 & 11 & & 3 & 6 & & 4 & 8 & \\
\hline Other & 13 & 13 & & 5 & 6 & & 7 & 12 & \\
\hline Not Reported & 4 & 2 & & 0 & 3 & & 1 & 2 & \\
\hline \multicolumn{10}{|l|}{ Treatment Stage } \\
\hline Newly Diagnosed & 12 & 20 & 0.47 & 13 & 13 & 0.04 & 10 & 8 & 0.55 \\
\hline In Treatment & 254 & 249 & & 137 & 140 & & 130 & 163 & \\
\hline Finished Therapy & 100 & 98 & & 76 & 44 & & 39 & 55 & \\
\hline Not Receiving Treatment & 30 & 25 & & 7 & 12 & & 11 & 20 & \\
\hline Not Reported & 2 & 3 & & 0 & 0 & & 0 & 2 & \\
\hline \multicolumn{10}{|l|}{ Education } \\
\hline Less than High School & 20 & 17 & 0.23 & 7 & 5 & 0.22 & 8 & 9 & 0.84 \\
\hline Some High School & 41 & 35 & & 17 & 11 & & 13 & 21 & \\
\hline
\end{tabular}


Table 2 Demographic comparisons of respondents who are Never, Prior, and Current Users of cannabis before and after legalization of recreational cannabis in Canada (Continued)

\begin{tabular}{|c|c|c|c|c|c|c|c|c|c|}
\hline & \multicolumn{3}{|c|}{ Never Users } & \multicolumn{3}{|c|}{ Prior Users } & \multicolumn{3}{|c|}{ Current Users } \\
\hline & Before & After & $p$ & Before & After & $p$ & Before & After & $p$ \\
\hline & $n=398$ & $n=395$ & & $n=233$ & $n=209$ & & $n=190$ & $n=248$ & \\
\hline High School/GED & 72 & 84 & & 29 & 35 & & 41 & 57 & \\
\hline Some College & 51 & 72 & & 59 & 36 & & 47 & 51 & \\
\hline College Graduate & 105 & 92 & & 67 & 73 & & 49 & 64 & \\
\hline Graduate Degree & 104 & 92 & & 48 & 45 & & 29 & 46 & \\
\hline Not Reported & 5 & 3 & & 6 & 4 & & 3 & 0 & \\
\hline
\end{tabular}

IQR interquartile range

${ }^{a}$ Age was calculated using a 2-sample $t$ test

b $p$ values were calculated using the chi-square test of independence and did not include 'Other' and 'Not Reported' categories

including 12 out of 248 (4.8\%) who stated their motivation for taking it was purely recreational. Thus, among Current Users, 68\% before legalization and 60\% after legalization had purely medicinal motives for taking cannabis products. This difference was not statistically significant ( $p$-value $>0.05)$. There were no changes in medical authorization prevalence, products used, symptom-related reasons for use, or where cannabis was obtained from before to after recreational legalization of cannabis.

After legalization, Current Users reported more problems getting cannabis (18\% post-legalization compared to $8 \%$ pre-legalization, $\mathrm{p}$-value $<0.01$ ) with the most common barriers cited as lack of available dispensaries $(n=19)$, lack of preferred product $(n=15)$, and cost $(n=$ 4) (Table 6).

\section{Discussion}

\section{After legalization}

Our results showed that the most common target symptoms patients reported taking cannabis products to help with were pain (58\%), insomnia (42\%), anxiety (36\%), and nausea (33\%). The results of this study are strikingly similar to two 2019 reports from the US. One report described a retrospective review of ambulatory palliative care clinic patients from New Hampshire and Vermont, and found a 27\% current cannabis use rate, primarily for medical purposes. $\mathrm{Pa}-$ tients were often treating multiple symptoms: pain (59\%), anorexia (19\%), insomnia (17\%), nausea (16\%), anxiety (10\%) and depression (6\%) [24]. It would be expected that a palliative care population would be more likely to be symptomatic than our unselected cancer centre-attending population, and therefore be more likely to use medical cannabis, yet our study reported the same prevalence and reasons for use. Very similar results were reported in an ambulatory Seattle cancer patient study [25].
Our results showed that Current Users often took multiple forms of cannabis products, but used oils the most $(70 \%)$ followed by smoking (64\%), eating (48\%), vaporizing (33\%) and topically (29\%). Consistent with our findings, a similar US study of cancer centre patients showed that the prevalence of using cannabis via inhalational and oral routes were equal [25].

Prior Medical Users reported multiple reasons for stopping taking cannabis, including ineffectiveness; intolerable side effects; and safety, and were slightly older (64 yrs) than Current Users (62 yrs). A 2017 systematic review reported that cannabinoids were less effective in managing chemotherapy side effects in older patients than in younger patients [5]. Participants in clinical trials using fixed doses of cannabisbased products also consistently report multiple side effects [5]. Our results with respect to side-effects and stopping taking cannabis are consistent with these studies.

The similarity in results between studies conducted in the US and Canada suggest that other countries considering legalization can expect similar patterns.

\section{Comparison between before and after legalization surveys}

Comparing our two surveys, we found that legalization was associated with a $26 \%$ increase in the prevalence of current cannabis use, from $23.1 \%$ to $29.1 \%(p=0.01)$. One explanation for this increase might be that in the run-up to legalization news and media outlets were filled with articles about dispensaries opening and closing, [18, 26, 27] products available, [28, 29], and new research [30-33], which may have emboldened more patients to try cannabis. Despite both surveys being anonymous, they may also have felt more comfortable disclosing recreational motivation for use.

Though there are places where both medical and recreational access to cannabis are legal, we are not aware 
Table 3 Descriptions of cannabis use among respondents who are Prior and Current Users comparing before and after recreational legalization of cannabis in Canada

\begin{tabular}{|c|c|c|c|c|c|c|}
\hline & \multicolumn{3}{|c|}{ Prior Users } & \multicolumn{3}{|c|}{ Current Users } \\
\hline & Before & After & $p$ & Before & After & $p$ \\
\hline & $n=233$ & $n=209$ & & $n=190$ & $n=248$ & \\
\hline \multicolumn{7}{|l|}{ Medical Authorization } \\
\hline No & 199 & 183 & 0.48 & 128 & 178 & 0.35 \\
\hline Yes & 32 & 24 & & 58 & 66 & \\
\hline Not Reported & 2 & 2 & & 4 & 4 & \\
\hline \multicolumn{7}{|l|}{ Product ${ }^{a}$} \\
\hline Smoked & 174 & 141 & 0.81 & 105 & 159 & 0.92 \\
\hline Oils & 75 & 75 & & 139 & 174 & \\
\hline Eating & 83 & 63 & & 86 & 119 & \\
\hline Vaporized & 14 & 11 & & 61 & 82 & \\
\hline Cream & 21 & 13 & & 46 & 71 & \\
\hline Tablets & 10 & 10 & & 24 & 29 & \\
\hline Drinking & 3 & 2 & & 16 & 25 & \\
\hline Mouth Spray & 3 & 1 & & 9 & 12 & \\
\hline Suppositories & 4 & 1 & & 6 & 14 & \\
\hline Other & 6 & 6 & & 16 & 16 & \\
\hline Not Reported & 0 & 5 & & 0 & 0 & \\
\hline \multicolumn{7}{|c|}{ What do you use it for? ${ }^{\text {a }}$} \\
\hline Recreational Use & 152 & 121 & 0.78 & 60 & 99 & 0.79 \\
\hline Pain & 51 & 57 & & 118 & 143 & \\
\hline Cancer Treatment & 25 & 30 & & 99 & 116 & \\
\hline Insomnia & 31 & 28 & & 77 & 104 & \\
\hline Nausea & 30 & 25 & & 74 & 81 & \\
\hline Anxiety & 22 & 20 & & 69 & 89 & \\
\hline Lack of Appetite & 16 & 12 & & 59 & 68 & \\
\hline Depression & 11 & 7 & & 32 & 48 & \\
\hline Tiredness & 10 & 6 & & 24 & 36 & \\
\hline Drowsiness & 3 & 1 & & 16 & 18 & \\
\hline Other & 7 & 5 & & 15 & 12 & \\
\hline Not Reported & 0 & 4 & & 0 & 0 & \\
\hline \multicolumn{7}{|c|}{ Where do you get it from? ${ }^{a}$} \\
\hline From a friend & 171 & 143 & 0.33 & 85 & 134 & 0.40 \\
\hline Dispensary & 46 & 52 & & 114 & 132 & \\
\hline Licensed Producer & 13 & 16 & & 28 & 41 & \\
\hline Grow it myself & 4 & 7 & & 17 & 26 & \\
\hline Other & 15 & 12 & & 11 & 17 & \\
\hline Not Reported & 5 & 5 & & 0 & 3 & \\
\hline \multicolumn{7}{|c|}{ Problems in getting Cannabis? } \\
\hline No & 184 & 164 & 0.64 & 172 & 201 & $<0.01$ \\
\hline Yes & 11 & 12 & & 15 & 44 & \\
\hline Not Reported & 38 & 33 & & 0 & 3 & \\
\hline
\end{tabular}

${ }^{a} p$ values were calculated using the chi-square test of independence and did not include 'Other' and 'Not Reported' categories 


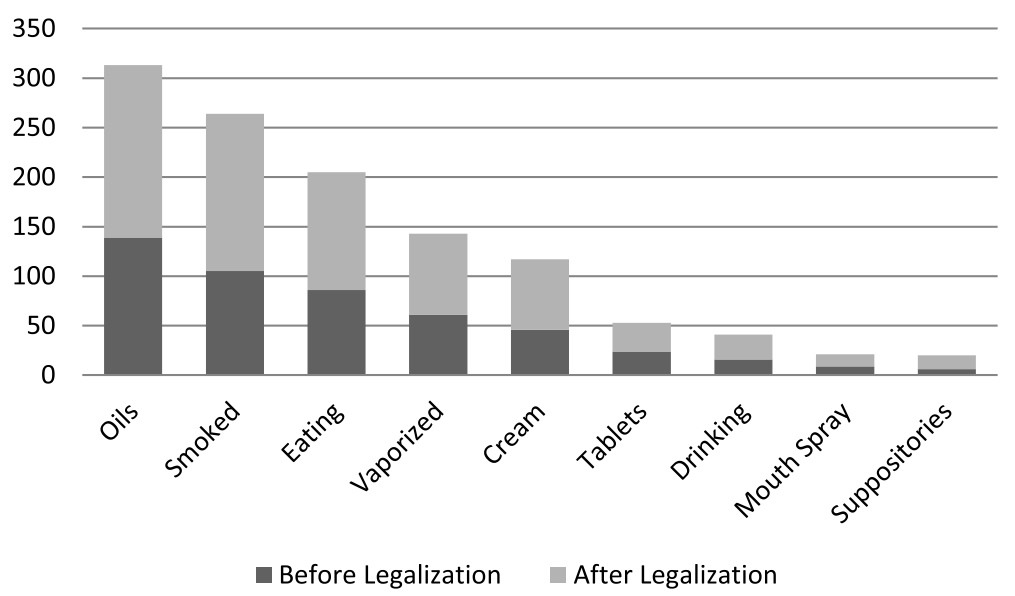

Fig. 3 Modes of Administration (Products) of Cannabis

of any data from other jurisdictions legalizing access to recreational cannabis in the setting of a separate established medical supply system.

Despite the increase in current users, the choice of cannabis products and reasons for taking them remained much the same between both surveys. The high frequency of reporting use for multiple symptoms strengthens the suggestion that cannabis products should be further studied for potential to reduce polypharmacy in symptomatic cancer patients. Use of cannabis as a form of cancer treatment also remained one of the most common reasons for cannabis use between surveys, and is concerning considering the lack of good clinical trial evidence for any survival benefit from cannabinoid use in cancer.

Our survey reported that only one third of current users who reported using cannabis for medical purposes had the medical authorization necessary for accessing the official medical access system.

Our study identified some problems that impacted medical users immediately following recreational legalization. We found that unlicensed dispensaries and other illegal sources were much more commonly used than the legal medical system, despite their lack of reliable labelling and absence of quality control. The results showed an increase in the prevalence of current cannabis use and also in problems accessing medical cannabis after legalization.

There were multiple reported barriers to use of the legal medical access system, reported by both survey cohorts. Patients who wished to buy high quality legal medical cannabis had to negotiate the online system of access, including getting a medical authorization and waiting for processing of their registration. Respondents from the second survey identified the lack of legalization of certain products (primarily edibles), as their reason for preferring to continue to use illegal sources. Other reported barriers included the need to have a credit card and a stable address for delivery of product, and also difficulties in deciding what to order without the benefit of face-to-face interaction with a salesperson. Medical users' access to appropriate products may also have been impeded by the fact that staff in recreational dispensaries are prohibited by law from providing medical advice.

The complexities of having two different licensing systems, and confusion between medical and recreational use made it difficult for patients and health care providers to figure out where to access reliable information and product suitable for medical purposes. It should be mentioned that $\mathrm{BC}$ was not unique in this respect in Canada [17, 34].

Similarly, respondents from the second survey identified the lack of legalization of certain products (primarily edibles), as their reason for accessibility barrier.

\section{Implications and suggestions}

Other jurisdictions planning to legalize recreational cannabis should consider the impact it might have on medical cannabis users. Medical and recreational use of cannabis often overlaps, at least in cancer patients, and it is concerning that many patients report believing/hoping that cannabis might help treat their cancer. Though much clinical research remains to be done, there is sufficient information available from credible sources (e.g. Health Canada) about doses, indications for medical use, and potential harms for appropriate guidance be created that should be made available in all vendor locations, irrespective of vendor focus.

\section{Strengths and limitations}

Results of this study provide new insights into cannabis use among cancer patients in British Columbia. This study is the first to provide data on the impact of recreational legalization on medical users. Strengths of this 
Table 4 Current Users' representative quotes on problems in getting access to cannabis after legalization

Theme

Specific items from dispensaries not available

\section{Representative Quotes}

- -Very hard to get CBD oil

- -The removal of CBD and topicals from the dispensary is stupid and cruel and harming people who need it.

- -Since cannabis has been legalized it is impossible to get certain products, or preferred brands.

- -Suppositories not legal and won't be in $100 \mathrm{mg}$ doses when it becomes legal.

- -Other than the gummies I can't get anymore, so I switched to oil.

- -Hard to source good edibles with consistent dosage.

- -Hard to find eatables.

- -Hard time getting stronger dosages.

- -Getting CBD was hard at first, everyone was producing THC now it is easy to get.

- -Edibles were banned from dispensaries, plus tonics.

- -Edibles used to be available but now have stopped.

- -Edibles (chocolates, etc.) no longer available; I make my own using oils.

- -Do not smoke, quit over 2 years ago. Would use edibles more if they were legal and more easily available. Use oil if available. Know a person that has medical, but doctors not get anymore.

- -Because I can't smoke it anymore and edibles are illegal.

- -A little, edibles should be legalized now.

- -January 2019 - no legal access in my city for legal drug! I can't find edibles and that's what I want

Issues with dispensaries and access to products
-Increased demand = decreased supply inconvenience of many dispensaries not licensed, Lack of access to licensed provider /lack of access to standardized product need/waiting high dose CBD difficult to find.

- -Slow delivery.

- - The dispensary in my residential neighborhood is closed - inconvenient to go to another location for it.

- -With licensing, reliable distributors closed down and sub-par, criminal-run dispensaries were left open only since recreational use was legalized!!! Prior to legalization I had 3 good sources in my city but they were forced to close. I traveled to Kamloops to get some product but they were out of what I needed. There should be some special need recognized for the use of medical cannabis! There was no problem with quality of the cannabis I use for medical purposes - nobody refines that stuff in their basement. I tried ordering it online and that was an exercise in futility! We NEED better access to it for medical use. And be more affordable. Thank you. (I will not give my \$ to these establishments).

- -Legally, not enough access.

- -Licensed producer (BC Gov) often has supply issues.

- Initially I was able to buy the THC Pheonix tears through a dispensary. After it was legalized the dispensary closed + I then had to source it from a friend who makes it for himself. He had lymphatic cancer and used only -THC he is now cancer free.

- -No dispensaries in Prince George.

- -Due to the onerous, cumbersome, and poorly thought out method of licensing, all the local dispensaries have closed.

- -Legalization has prevented all dispensaries I used from re-opening - apparently due to local city council morons. Perfectly good system of dispensaries destroyed by political morons abusing their powers at local level since legalization.

- -Licensing regulations in my area have caused closure of stores and none have reopened yet.

- -Legal cannabis stores still not open.

- -Easy to get on the street - cannot get a retail.

- -Dispensary unable to sell to me now! Why is that??? Where can one purchase?
Frequency Proportion

$\begin{array}{ll}-16 & -0.36\end{array}$


Table 4 Current Users' representative quotes on problems in getting access to cannabis after legalization (Continued)

\begin{tabular}{|c|c|c|c|}
\hline Theme & Representative Quotes & Frequency & Proportion \\
\hline & $\begin{array}{l}\text { - - l live in northern } B C=\text { medical dispensary used to mail out, now since legalization } \\
\text { they don't = access down, cost increases }\end{array}$ & & \\
\hline \multirow{5}{*}{$\begin{array}{l}\text { Issues in getting medical } \\
\text { authorization }\end{array}$} & - -Trouble getting authorization. & -5 & -0.11 \\
\hline & - -Need Dr's note. & & \\
\hline & $\begin{array}{l}\text { - -Medical form requires re-authorization every } 6 \text { months and has been struggle to get } \\
\text { oncologist to sign and submit. It is January now and still waiting for request since } \\
\text { October. }\end{array}$ & & \\
\hline & $\begin{array}{l}\text { - -Since cannabis has been legalized it is so difficult to get a general practitioner, or } \\
\text { arthritis specialist to give you a prescription, and otherwise you need to pay some } \\
\text { cannabis doctor for a prescription and it is cost prohibitive cost wise for us low income } \\
\text { patients. }\end{array}$ & & \\
\hline & - -Legal restrictions. & & \\
\hline \multirow[t]{3}{*}{ Issues with cost } & - -It is very expensive. & -3 & -0.07 \\
\hline & - -Friends not always reliable, outlets are too expensive. & & \\
\hline & - -200 mg suppositories are $\$ 7$ each $\times 3$ daily is too much $\$$ & & \\
\hline
\end{tabular}

study include the close comparability of characteristics among participants in both cohorts. Open-ended questions in the survey allowed participants to share their experience with regards to barriers in obtaining cannabis, which added depth to understanding of the data.

As with all surveys, those that responded to the survey may not be representative of the surveyed population, thus our $27 \%$ response rate could reflect a sampling bias. The close matching of the demographics of respondents to the two consecutive surveys however gives us confidence that the differences demonstrated between the

Table 5 Reasons respondents who are Prior Users ceased cannabis use

\begin{tabular}{|c|c|c|c|}
\hline & \multicolumn{3}{|c|}{ Prior Users } \\
\hline & $\begin{array}{l}\text { Before } \\
n=233\end{array}$ & $\begin{array}{l}\text { After } \\
n=209\end{array}$ & $p$ \\
\hline \multicolumn{4}{|l|}{ Why did you stop? ${ }^{a}$} \\
\hline Not effective & 31 & 42 & 0.69 \\
\hline Intolerable Side-Effects & 26 & 25 & \\
\hline Cost & 27 & 19 & \\
\hline Advice from Doctor & 9 & 7 & \\
\hline Safety Concerns & 33 & 25 & \\
\hline Other: & 3 & 4 & \\
\hline Difficult to access & 13 & 22 & \\
\hline No longer needed & 4 & 5 & \\
\hline Contraindication & 18 & 18 & \\
\hline Lost interest & 29 & 35 & \\
\hline Not since youth (20+ years ago) & 18 & 20 & \\
\hline Did not enjoy it & 46 & 15 & \\
\hline Not Reported & 18 & 9 & \\
\hline
\end{tabular}

a $p$ values were calculated using the chi-square test of independence and did not include unspecified 'Other' and 'Not Reported' categories two cohorts' responses reflect actual change. As the data was collected by self-report, and despite the surveys being anonymous, there may have been more openness in reporting recreational motives for cannabis use in the second cohort, with legalization of recreational use reducing stigma. There may also have been a recall bias about respondents' prior cannabis use.

Another limitation is that there was no control group, and it is possible that the differences seen between the two cohorts may have been due to factors other than recreational legalization. The time difference was however only 5 months.

Though unlikely to have been a major confounder, there was potential for confusion about the definitions of routes of ingestion between our two survey cohorts that we were not aware of at the time the surveys were designed and tested by our patient partners. At the time of the post-legalization survey, gel capsules filled with oil were just becoming available legally and could possibly have been classified by some respondents as "edibles" rather than oils, whereas most "edibles" available illegally to the pre-legalization cohort were in the form of cookies, brownies and candies which were (and remain) illegal. Also, legally obtained oils could conceivably have been compounded for topical use by the respondents.

\section{Conclusions}

This study adds to the literature on medical cannabis use in cancer patient populations and suggests that legalization of recreational cannabis in Canada had an effect on medical users, where there was a separate established safe medical supply system. Our results suggest a correlation between increased cannabis use in cancer patients and legalization of recreational cannabis, as many patients using cannabis-based products for medical purposes access them through routes outside 
Table 6 Reasons Prior and Current Users had problems obtaining cannabis

\begin{tabular}{|c|c|c|c|c|c|c|}
\hline & Prior Us & & & Current & & \\
\hline & Before & After & $p$ & Before & After & $p$ \\
\hline & $n=11$ & $n=12$ & & $n=15$ & $n=44$ & \\
\hline Cost & 1 & 1 & 0.33 & 2 & 4 & 0.30 \\
\hline Closed Dispensaries/No available legal access & 4 & 3 & & 2 & 19 & \\
\hline Difficulty getting medical authorization & 2 & 1 & & 2 & 3 & \\
\hline Specific products (e.g. edibles) or strengths unavailable & 0 & 3 & & 3 & 15 & \\
\hline Other & 2 & 1 & & 2 & 0 & \\
\hline Not reported & 2 & 3 & & 4 & 3 & \\
\hline
\end{tabular}

${ }^{a} p$ values were calculated using the chi-square test of independence and did not include 'Other' and 'Not Reported' categories

the official medical access process. Separating medical and recreational access programs is not important for many patients, and making sure that legal access routes have clear advantages for patients over existing illegal sources will be crucial to success for any legalization initiative. Product range, price, face to face contact with vendors, and complexity of access all need to be considered if illegal supply systems are to be eliminated and the benefits of regulation are to be realized.

\section{Abbreviations}

AIDS: Acquired immunodeficiency syndrome; BC: British Columbia;

BCC: British Columbia Cancer; CBD: Cannabidiol; IQR: Interquartile Range;

THC: Tetrahydrocannabinol; US: United States

\section{Acknowledgements}

We are thankful for our colleagues at all six BC Cancer Centers who provided insights and assisted us. We also would like to extend our gratitude to all of the participants who took time to complete and return the surveys.

\section{Authors' contributions}

Authors of this paper, PH and MG, collected the data. MG and NA analysed the data. MG and NA were responsible for the data accuracy and database integration. All authors contributed to writing the manuscript. MG and NA prepared the figures and tables. All authors had full access to the data and contributed in writing the results, and interpretations. All authors have read and approved the manuscript.

\section{Funding}

The BC Cancer Foundation provided funding for this research. The Foundation had no role in the study design, analysis or interpretation of the data.

\section{Availability of data and materials}

The datasets used and/or analysed during the current study are stored on a secure database at BC Cancer and are available from the corresponding author on reasonable request.

\section{Ethics approval and consent to participate}

This study was approved by the University of British Columbia Research Ethics Board (H18-01638). All the necessary written consents were obtained from the participants.

\section{Consent for publication}

Not applicable.

\section{Competing interests}

We have read and understood BMC Health Services' policy on disclosing conflicts of interest and declare that we have none.

The authors declare that they have no competing interests.
Received: 10 February 2020 Accepted: 22 September 2020

Published online: 27 October 2020

\section{References}

1. Velasco G, Sánchez C, Guzmán M. Anticancer mechanisms of cannabinoids. Current Oncology. 2016;23:23-32 Multimed Inc.

2. Maida V, Daeninck PJ, et al. Current Oncology. 2016;23:398-406 Multimed Inc.

3. Aggarwal SK, Blinderman CD. Cannabis for Symptom Control \#279. J Palliat Med. 2014 May 1;17(5):612-4.

4. Bar-Lev Schleider L, Mechoulam R, Lederman V, Hilou M, Lencovsky O, Betzalel $\mathrm{O}$, et al. Prospective analysis of safety and efficacy of medical cannabis in large unselected population of patients with cancer. Eur J Intern Med. 2018;49:37-43.

5. Bridgeman MB, Abazia DT. Medicinal cannabis: History, pharmacology, and implications for the acute care setting. P T. 2017;42(3):180-8.

6. Walsh Z, Callaway R, Belle-Isle L, Capler R, Kay R, Lucas P, et al. Cannabis for therapeutic purposes: Patient characteristics, access, and reasons for use. Int J Drug Policy. 2013;24(6):511-6.

7. Webb CW, Webb SM. Therapeutic benefits of cannabis: a patient survey. Hawaii J Med Public Health. 2014;73(4):109-11.

8. Koch M, Varela L, Kim JG, Kim JD, Hernández-Nuño F, Simonds SE, et al. Hypothalamic POMC neurons promote cannabinoid-induced feeding. Nature. 2015:519(7541):45-50.

9. Hill KP. Medical marijuana for treatment of chronic pain and other medical and psychiatric problems: A clinical review. JAMA. 2015:313:2474-83.

10. Government of Canada. Understanding the New Access to Cannabis for Medical Purposes: Health Canada; 2016. https://www.canada.ca/en/healthcanada/services/publications/drugs-health-products/understanding-newaccess-to-cannabis-for-medical-purposes-regulations.html. Accessed $28 \mathrm{Sept}$ 2020.

11. Government of Canada. What you need to know about cannabis: Health Canada; 2019. https://www.canada.ca/en/services/health/campaigns/ cannabis/canadians.html. Accessed 28 Sept 2020.

12. The Economist. Drug legalization in Uruguay: The experiment: The Economist; 2013. https://www.economist.com/the-americas/2013/08/03/theexperiment. Accessed 28 Sept 2020.

13. Castaldi M, Llambias F. Uruguay becomes first country to legalize marijuana trade: Reuters; 2013. https://www.reuters.com/article/us-uruguay-marijuanavote/uruguay-becomes-first-country-to-legalize-marijuana-tradeidUSBRE9BA01520131211. Accessed 28 Sept 2020.

14. Government of Canada. Health Canada finalizes regulations for the production and sale of edible cannabis, cannabis extracts and cannabis topicals - Canada.ca: Health Canada; 2019. https://www.canada.ca/en/ health-canada/news/2019/06/health-canada-finalizes-regulations-for-theproduction-and-sale-of-edible-cannabis-cannabis-extracts-and-cannabistopicals.html. Accessed 28 Sept 2020.

15. What you need to know about cannabis - Canada.ca. https://www.canada. ca/en/services/health/campaigns/cannabis/canadians.html. Accessed 28 Sept 2020.

16. Barrus DG, Capogrossi KL, Cates SC, Gourdet CK, Peiper NC, Novak SP. et al., Tasty THC: Promises and Challenges of Cannabis Edibles. Methods Rep RTI Press. 2016. https://doi.org/10.3768/rtipress.2016.op.0035.1611. 
17. Doherty B. Ontario is holding lottery for cannabis stores on Friday. Here's what the rest of the country tried and how it turned out. The Star. https:// www.thestar.com/news/cannabis/2019/01/10/ontario-is-holding-a-lotteryfor-cannabis-stores-on-friday-heres-what-the-rest-of-the-country-tried-andhow-it-turned-out.html. Accessed 28 Sept 2020.

18. Eegland N. B.C. to get just a single cannabis store on day one of legalization. Vancouver Sun. 2018. https://vancouversun.com/cannabis/ cannabis-news/partaking-some-time-b-c-to-get-just-a-single-cannabis-storeon-day-one-of-legalization. Accessed 28 Sept 2020.

19. Hawley P, Gobbo M. Cannabis Use in Cancer: A Survey of the Current State at BC Cancer. Curr Oncol. 2019;26(4):425-32.

20. Government of Canada. Canadian cannabis survey 2017 - Summary: Health Canada; 2017. https:/www.canada.ca/en/health-canada/services/ publications/drugs-health-products/canadian-cannabis-survey-2017summary.html. Accessed 28 Sept 2020.

21. Martell K, Fairchild A, Legerrier B, Sinha R, Baker S, Liu H, et al. Rates of cannabis use in patients with cancer. Curr Oncol. 2018;25(3):219-25.

22. Harris PA, Taylor R, Thielke R, Payne J, Gonzalez N, Conde JG. Research electronic data capture (REDCap)-A metadata-driven methodology and workflow process for providing translational research informatics support. J Biomed Inform. 2009;42(2):377-81.

23. Harris PA, Taylor R, Minor BL, Elliott V, Fernandez M, O'Neal L, et al. The REDCap consortium: Building an international community of software platform partners. Journal of Biomedical Informatics. 2019;95:103208 Academic Press Inc.

24. Wilson M, Masterson E, Broglio K. Cannabis Use Among Patients Prescribed Opioids in a Palliative Care Clinic (S875). J Pain Symptom Manage. 2019; 57(2):522.

25. Pergam SA, Woodfield MC, Lee CM, Cheng G-S, Baker KK, Marquis SR, et al. Cannabis use among patients at a comprehensive cancer center in a state with legalized medicinal and recreational use. Cancer. 2017;123(22):4488-97.

26. Bains C. Lawyer urges B.C. Supreme Court to toss application to close medical marijuana dispensaries: National Post; 2018. https://nationalpost. com/news/canada/b-c-lawyer-says-medical-marijuana-users-have-right-tobuy-pot-just-like-others. Accessed 28 Sept 2020.

27. Courtenay P. Government of B.C. approves the first private adult-use cannabis dispensary. The Georgia Straight. 2018. https://www.straight.com/ cannabis/1158891/government-bc-approves-first-private-adult-use-cannabisdispensary. Accessed 28 Sept 2020

28. Wingrove J, Quinn G, Owram K. Canada may not be ready for edible pot sales by October deadline: Financial Post; 2019. https://business. financialpost.com/cannabis/edible-pot-sales-could-miss-canadiangovernments-october-target. Accessed 28 Sept 2020.

29. Rodriguez J. Trying cannabis for the first time? Here's everything you can expect: CTV News; 2018. https://www.ctvnews.ca/canada/trying-cannabisfor-the-first-time-here-s-everything-you-can-expect-1.4136607. Accessed 28 Sept 2020.

30. Fayerman P. B.C. to lead first national cannabis clinical trial for symptom relief: Vancouver Sun; 2019. https://vancouversun.com/news/local-news/b-ccancer-to-lead-first-national-cannabis-clinical-trial-for-symptom-relief. Accessed 28 Sept 2020.

31. Baker R. New UBC pot professor to research potential of cannabis in treating opioid addiction: CBC News; 2018. https://www.cbc.ca/news/ canada/british-columbia/ubc-cannabis-professor-to-research-opioidtreatment-1.4919245. Accessed 28 Sept 2020.

32. Young L. How long does cannabis stay in your system? Global News; 2019. https://globalnews.ca/news/4988296/how-long-cannabis-lasts-body/. Accessed 28 Sept 2020.

33. Fitch C. Cannabis still has mystery, Canada's first weed-only academic researcher says: National Post; 2018. https://nationalpost.com/pmn/news$\mathrm{pmn} /$ canada-news-pmn/scientist-hopes-to-revolutionize-cannabis-researchin-groundbreaking-role. Accessed 28 Sept 2020.

34. Murphy J. Why is Canada running out of marijuana? BBC News; 2018. https://www.bbc.com/news/world-us-canada-46200873. Accessed 28 Sept 2020

\section{Publisher's Note}

Springer Nature remains neutral with regard to jurisdictional claims in published maps and institutional affiliations.

\section{Ready to submit your research? Choose BMC and benefit from}

- fast, convenient online submission

- thorough peer review by experienced researchers in your field

- rapid publication on acceptance

- support for research data, including large and complex data types

- gold Open Access which fosters wider collaboration and increased citations

- maximum visibility for your research: over $100 \mathrm{M}$ website views per year

At BMC, research is always in progress.

Learn more biomedcentral.com/submissions 